\title{
Marketing Relations and Communication Infrastructure Development in the Banking Sector Based on Big Data Mining
}

Submitted 19/08/19, 1st revision 28/09/19, 2nd revision 13/10/19, accepted 20/11/19

\author{
Ivanchenko O.V. ${ }^{1}$, Mirgorodskaya O.N. ${ }^{2}$, Baraulya E.V. ${ }^{3}$, Putilina T.I. ${ }^{4}$
}

\begin{abstract}
:
Purpose: The article aims to study the methodological tools for applying the technologies of intellectual analysis of big data in the modern digital space, the further implementation of which can become the basis for the marketing relations concept implementation in the banking sector of the Russian Federation 'economy.

Structure/Methodology/Approach: For the marketing relations development in the banking sector in the digital economy, it seems necessary: firstly, to identify the opportunities and advantages of the big data mining in banking marketing; secondly, to identify the sources and methods of processing big data; thirdly, to study the examples of the big data mining successful use by Russian banks and to formulate the recommendations on the big data technologies implementation in the digital marketing banking strategy.

Findings: The authors ' analysis showed that big data technologies processing of open online and offline sources of information significantly increases the data amount available for intelligent analysis, as a result of which the interaction between the bank and the target client reaches a new level of partnership.

Practical Implications: Conclusions and generalizations of the study can be applied in the practice of managing financial institutions. The results of the study can be used by bank management to form a digital marketing strategy for long-term communication.

Originality/Value: The main contribution of this study is that the authors have identified the main directions of using big data in relationship marketing to generate additional profit, as well as the possibility of intellectual analysis of the client base, aimed at expanding the market share and retaining customers in the banking sector of the economy.
\end{abstract}

Keywords: Relationship marketing, digital space, data mining, big data, banking services.

JEL code: M31, M39.

Paper Type: Research article: Big Data Mining.

\footnotetext{
${ }^{1}$ Associate Professor, Department of Marketing and Advertising, Rostov State University of Economics (RINH), Rostov-on-Don, iovkmr@mail.ru

${ }^{2}$ Associate Professor, Department of Marketing and Advertising, Rostov State University of Economics (RINH), Rostov-on-Don, olyana_mon@mail.ru

${ }^{3}$ Associate Professor, Department of Commodity Research and Quality Management, Rostov State University of Economics (RINH), Rostov-on-Don, baraulyaev@yandex.ru

${ }^{4}$ Associate Professor, Chair of Commodity Research and Quality Management, Rostov State University of Economics (RINH), Rostov-on-Don, putilina.tat@mail.ru
} 


\section{Introduction}

Internet technology and social media are currently changing the business nature. Consumers are becoming more demanding and less loyal. In this regard, the priority of marketing relationships is to improve the customer experience. Using Artificial Intelligence in general and big data mining in particular helps to solve this problem. In a highly competitive market financial companies and banks are actively introducing information technology, including big data, machine learning, which leads to the banking product line expansion and takes interaction between the bank and the client to a new level. Financial products are changing under the influence of the cryptocurrencies emergence, the spread of which causes a change in regulation in the monetary circulation sphere.

In the framework of consumer orientation, the combined use of marketing strategy elements allows to provide the competitive advantages by improving the quality of individual relationships between the company and the end user (Ivanchenko, 2017). Big data technologies enable banks and companies to understand what consumers are doing and buying in a modern information and communication space. Thanks to this, the banks receive a comprehensive portrait of the consumer, on the basis of which it is possible to form a personalized offer for an individual client. Hence, the improvement of technologies for the big data mining application in the marketing of relations in the banking services market seems quite relevant (Polyakova et al., 2019; Rupeika-Apoga et al., 2018).

The purpose of the study is to analyze the methodological tools for applying big data technologies in the modern digital space, the further implementation of which can become the basis for the marketing relations concept implementation in the banking sector of the economy. The subject of the study is the relationship that arises between manufacturers and consumers of banking services as a result of big data mining use in the relationship marketing information and communication infrastructure development.

The working hypothesis of the study is the assumption that the processing of open online and offline sources of information using Big data technologies significantly increases the amount of data available for mining, as a result of which the interaction between the bank and the client reaches a new level of partnership, as banking institutions become full aggregators information in order to carry out the long-term transactions with target consumers. The scientific novelty of the study lies in the development of theoretical and methodological aspects of big data mining use in the marketing activities of banks, which allows the use of methodological tools for marketing relations to form the long-term communication with the target consumer anywhere in space and time.

\section{Methods of Research}


The empirical basis of the article comprise the results of a practice-oriented study on relevant aspects of big data mining; as well as scientific and practical study of these aspects, conducted by modern scientists and practitioners. Using the big data analytics digital transformation specific features marketing analysis methods in the field of banking services, it was possible to carry out a conceptual and theoretical generalization of marketing tools relationship in the modern information and communication space.

\section{Results}

Currently, Big data is a modern technological opportunity for the analysis of large data arrays. "Big data" refers to the huge volumes of internal and external data of various structures, while Big data consists of three elements:

- data;

- analytics;

- technology (Romanov and Pyatigorskiy, 2015).

The main sources of large amounts of data are: Internet documents; social media; blogs, audio/video sources; measuring devices. At the same time, data without analytics, without revealing hidden and unobvious dependencies is not big data, in turn, the technologies allowing not only to store large amounts of data, but also to analyze it are needed for the managerial decisions formation. Such technologies arose in Internet giants, since it was they who were the first to encounter the problem of storing a large amount of data and analyzing it for subsequent monetization.

Before machine learning algorithms begin to work, the data must first be selected and processed. For this, people are still needed. Work on data analysis is becoming more complicated every day. Typical current arrays include the most diverse sources: posts on social networks, product reviews, search trends, company data, commercial transactions, bank account and plastic card transactions, satellite imagery, etc. All this information needs to be processed before they become of value for the marketing strategy.

Big data is, first of all, the "raw" material for the marketer, which, when treated correctly, can turn into "Smart Data," that is, those that will identify the new trends in consumer behavior and formulate a more accurate offer for them. Many companies collect huge flows of audience data - both static, demographic, and transactional - but do they get new knowledge from them about different segments of the target audience? Big data analysis and processing is carried out on the basis of the following main methods:

1. Data mining: A large group of methods that integrate mathematical tools and information technology.

2. Crowdsourcing: Getting data from an unlimited range of diverse sources. 
3. A/B testing: From the control set of elements, one element is changed and a comparison is made with other similar sets. Carrying out such tests determines which parameter changes affect the control population more. Big data makes it possible to carry out a huge number of comparisons and get a reliable result.

4. Predictive analytics: Making decisions based on the scenario development for the future behavior of the analysed object.

5. Machine learning (artificial intelligence): Construction of self-learning algorithms for artificial systems based on empirical analysis of information.

6. Network analysis: A study of social networks, when statistics provide the basis for analyzing the relationships between social media users and their communities (Bondarenko et al., 2018).

Big data technologies have already entered business practice and are being actively mastered by leading IT companies (Sokolova, 2015). According to International Data Corporation (IDC), the amount of stored data in the world since 2010 has increased by 50 times. By 2020, it will have grown another 15 times and reach the level of $40 \mathrm{ZB}$ (zettabytes). Growth will mainly come from emerging markets. A variety of open online sources generate information data that becomes one of the valuable companies' assets.

In a highly competitive market financial companies and banks are actively implementing information technology, including Big data. This trend is pushing bank management to invest in IT infrastructure. Without developing their own IT and data management strategies, without entering the online services market, without creating trusting and long-term relationships with customers, banks will lose their business. According to experts, the choice of a reliable IT partner and ensuring effective corporate control over it will become a key element of the IT strategy for most banks in the coming years (Romanenko, 2018).

The banking market is an active user of Big data. It is possible to mention that that Big data in Russia is not a popular trend, but an established practice in the banking sector, as evidenced by examples of using Big data's technological capabilities in banks. So, "Sberbank" uses Big data to manage risks, fight fraud, segment and evaluate the creditworthiness of customers, personnel management, forecasting queues in branches, calculating bonuses for employees and other tasks. VTB24 uses big data to segment and manage customer outflows, generate financial statements and analyze reviews on social networks and forums. To do this, it uses Teradata, SAS Visual Analytics and SAS Marketing Optimizer solutions. Since 2013, AlfaBank has been using technologies to analyze social networks and users' site behavior, assess creditworthiness, predict customer churn, personalize content and secondary sales. To do this, the Oracle Exadata storage and processing platforms, Oracle Big data Appliance, and the Hadoop framework are used. Tinkoff Bank with the help of EMC Greenplum, SAS Visual Analytics and Hadoop manages risks, analyzes the needs of potential and existing customers. Big data is also involved in scoring, marketing and sales" (BDM, 2015). 
According to the Analytical Review, "The Russian Regional Development Bank analyzes the behavior of plastic card holders. This allows to identify the operations that are not typical for a particular client, thereby increasing the likelihood of detecting money theft from plastic cards. Another successful application of Big data is the Ural Bank for Reconstruction and Development, where the information base for customer analysis came into use, the bank started implying specialized credit offers, deposits and other services. During the year of using these technologies, the company's retail loan portfolio grew by $55 \%$ "(BDM, 2015). It can be concluded that the largest players in the banking market successfully combine the information resources of information analysis with the classic lines of marketing. The Big data technologies application takes marketing tools in the banking sector to a whole new level.

What is the use of big data analytics in relationship marketing? With its help it is possible to create new projects much faster, which are likely to become in demand among the target audience. Analytics helps to correlate the customer requirements with an existing or planned service and, thus, adjust it. Big data methods make it possible to evaluate the degree of current satisfaction of all users and each individual. Increasing customer loyalty is ensured by methods of processing big data. In general, attracting the target audience on the Internet is becoming easier thanks to the ability to control huge amounts of data.

The Forbes study found that $48 \%$ of marketers using Big data analysis do just that for in-depth analytics of consumer behavior. Forrester studies confirm this data: for $36 \%$ of specialists, data mining has become the main tool in developing client marketing strategies due to the ability to get new insights about consumer behavior (Izmailova, 2018). The main directions of using big data in relationship marketing for additional profit:

1. Customer segmentation: By fixing actions, purchases, customer characteristics, it is possible to understand what content will be of interest to each customer.

2. Increasing customer loyalty: Positive customer experience, personalized content and individual offers will give more benefits in the long range prospect.

3. Data visualization: Visualization is a way to transfer the data into graphical form, and infographics is a way to tell and consistently explain a topic. Visualization is one of the infographics key elements, but at the same time autonomous.

4. New product development: In case a financial company has a huge amount of information, predictive analysis can help with the introduction of a new product or service.

Table 1 summarizes the results of applying big data mining in the financial services market. Big data processing tools allow to make decisions regarding the line of banking products and also help in analyzing the competitors' offers; the target audience preferences and the most relevant service offerings, taking into account previous customer experience in the formation. 
The choice of a popular sales channel for banking services for consumers can be made on the basis of the huge array data analysis on previous sales. The gradual and inevitable transition of banks to online will further increase the marketers analyze the online customer data in future.

Table 1. Examples of the effectiveness of using big data analytics in the financial sector (compiled by authors on the basis of Vanin, 2016)

\begin{tabular}{|l|l|l|l|}
\hline Company & Data & Buisness process & The Effect \\
\hline Bank of TOP 50 & $\begin{array}{l}\text { Search queries } \\
\text { Web page content }\end{array}$ & $\begin{array}{l}\text { Credit scoring } \\
\text { accuracy to model }\end{array}$ \\
\hline Bank of TOP 60 & Social networks & $\begin{array}{l}\text { B2C Target } \\
\text { Marketing }\end{array}$ & $\begin{array}{l}+10 \% \text { accuracy of } \\
\text { cross-sell models }\end{array}$ \\
\hline Bank of TOP 10 & Payment Details & $\begin{array}{l}\text { B2B Target } \\
\text { Marketing }\end{array}$ & $\begin{array}{l}\text { Improving cross- } \\
\text { selling performance } \\
\text { for selected products }\end{array}$ \\
\hline $\begin{array}{l}\text { Insurance company } \\
\text { from TOP -5 }\end{array}$ & Social networks & $\begin{array}{l}\text { Application scoring } \\
\text { B2C Target } \\
\text { Marketing }\end{array}$ & $\begin{array}{l}+35 \% \text { to model } \\
\text { accuracy }\end{array}$ \\
\hline
\end{tabular}

Big data helps to make decisions on the most affordable price based on the analytics of a variety of financial reports and business indicators. For banking brands with a wide and diverse customer base, big data analysis provides information for making decisions on customizing prices across multiple consumer segments. The use of Big data information technologies, as well as the integration of offline and online communications, allows to get a comprehensive portrait of the consumer and predict the reaction of the target audience to the bank's offers. In general, the Big data analysis application in the banking services marketing will allow:

- to develop an accurate portrait of the target consumer and form a large number of look-alike target audiences;

- to make a forecast of customer attitudes towards a new banking product and selected advertising messages;

- to personalize the offers with high relevance at the "right" time;

- to reduce the cost of forming a marketing budget;

- to increase the loyalty of target consumers by increasing knowledge about the actual customers' needs.

\section{Discussion}

The projects for the intellectual analysis of the client base, aimed at expanding the market share and maintaining the bank's client base, may include:

- Client profile for integrated arrays of information using external data (enrichment).

- Understanding the behavior, needs, intentions of the client and their forecasting.

- Managing customer churn. 
- Monitoring of digital space in order to control the customers' opinion of a banking product.

- Identification of opinion leaders and analysis of their possible impact.

Immediate and most adequate response to customer actions using enriched customer data includes:

- Using the incoming communications capabilities.

- Monitoring of internal and external, in relation to the bank of events.

- Prompt communication at the time of the user action.

- Third-party data to determine the customer profile at the time the action was taken.

- Combination with existing marketing campaigns.

- Customized offers for customers.

Figure 1 shows the operation diagram of Big data for the Bank's Call Center. The call center operator has a complete picture of the client in real time, and as a result increased profits due to cross-sales, increased customer loyalty due to quality service, reduced customer churn due to prompts from speech analysis.

Figure 1. The Big data functioning diagram for the Bank's Call Center (compiled by authors on the basis of Nesterenko, 2014)

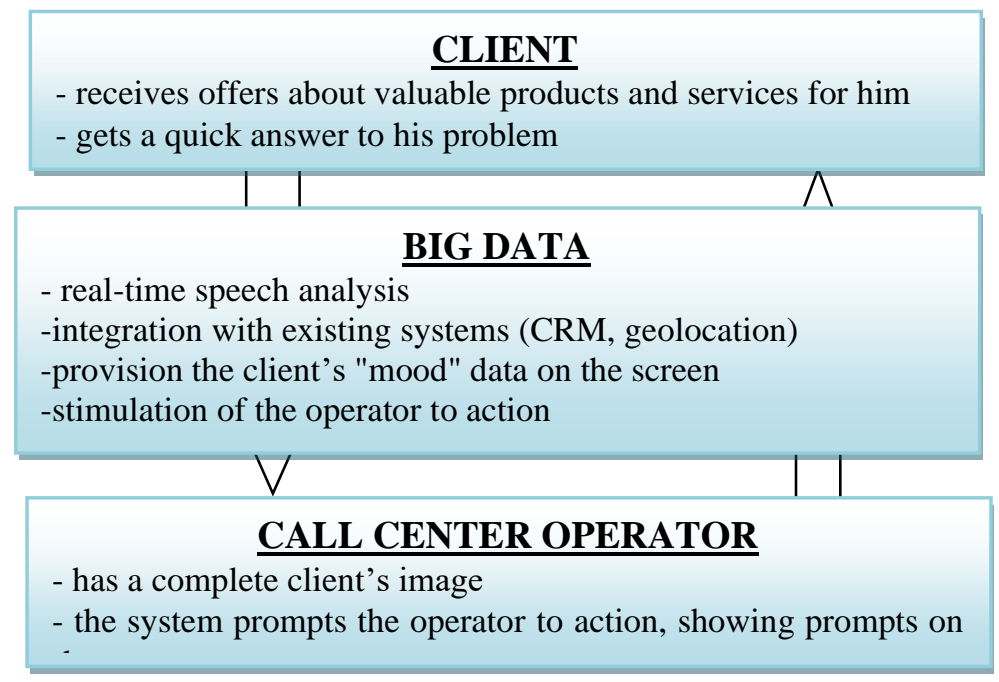

Thus, the analysis of big data increases the effectiveness of marketing campaigns in the banking services market based on predictive analytics, real-time research of customer preferences and analysis of historical indicators. Achieving the expected business effect is due to an increase in the client's life cycle, cross-upsell, effective customer retention and attraction. 
The benefits of using big data technologies develop the relationship marketing infrastructure in the following areas:

- The speed of creating the new goods and services satisfying the needs of customers is increasing.

- Making adjustments to an existing or planned service based on customer requirements.

- Assessment of individual customer satisfaction individually, as well as determination of current satisfaction of the entire consumers ' population.

- Deep analytics of data on regular customers increases their loyalty and ensures long-term relationships.

- Control over a huge amount of information ensures the target consumers ' attraction at the lowest cost.

\section{Conclusion}

Working with data, analytics and other related elements of data-driven relationship marketing regularly fall into the list of main trends. But the prevalence of this approach is still growing at a slow pace. Many marketers have little or no statistical apparatus at all and do not understand how to work with data. At the same time, the possibilities of an analytical approach in relationship marketing are significant. They will increase the campaigns' effectiveness at times, it's better to justify the events and identify previously invisible patterns.

Summarizing the above-said, we indicate that based on big data analytics, a bank can adjust the interface of its automated systems to an individual client. The technological banking processes re significantly accelerated. By analyzing social networks, banks can quickly assess the mood of customers, determine their attitude to new products and services, improve the quality of services provided, taking into account the consumers' views. Much information can be found by studying the users' behavior on a banking site. The projects to analyze the customer actions in mobile banking applications seem to be perspective as well. They can identify difficult moments in interaction with the banking system, as a result of which the interaction between the bank and the client reaches a new level of partnership.

The theoretical significance of the study is determined by the fact that its results can serve as a methodological basis for the development of the big data mining use in the marketing banks' activities. The practical significance of the study lies in the fact that the research results can be used by bank management to form a digital marketing strategy for long-term communication with the consumer anywhere in space and time. 


\section{References:}

BDM. 2015. Analytical review of the Big data market. Available online: https://habr.com/company/moex/blog/256747/.

Bondarenko, V.A., Ivanchenko, O.V., Sagoyan, A.S. 2018. The use of Big data technology in the relations marketing in the banking services market. Financial Economics, 6, 10281031.

Ivanchenko, O.V. 2017. Information and communication infrastructure in substantiating a company's marketing strategy in an unstable market. Financial Studies, 2(55), 141146.

Izmailova, M. 2018. Big data: Size does not matter. Available online: https://www.sostav.ru/publication/big-data-razmer-ne-imeet-znachenie-31028.html.

Nesterenko, S. 2014. Big data Technologies for Client Analytics. IBS Experience, available online: https://www.ibm.com/en/events/presentations/connect2014/ 12_connect14.pdf.

Polyakova, A.G., Loginov, M.P., Serebrennikova, A.I., Thalassinos, E.I. 2019. Design of a socio-economic processes monitoring system based on network analysis and big data. International Journal of Economics and Business Administration, 7(1), 130-139.

Romanenko, I. 2018. How Big data Banks Will Change. Available online: https://www.executive.ru/management/itforbusiness/1988007-kak-big-data-izmenyat-banki.

Romanov, K., Pyatigorsky, A. 2015. Why Big data is constantly confused with marketing and IT. Available online: https://vc.ru/marketing/12304-big-data-cases.

Rupeika-Apoga, R., Zaidi, H.S., Thalassinos, E.Y. and Thalassinos, I.E. 2018. Bank Stability: The Case of Nordic and Non-Nordic Banks in Latvia. International Journal of Economics and Business Administration, 6(2), 39-55.

Sokolova, A. 2015. How the big data market in Russia works. Available online: https://rb.ru/howto/big-data-in-russia/.

Vanin, S. 2016. The practice of using external data to improve the efficiency of working with clients. Available online: https://docplayer.ru/44609689-Praktika-ispolzovaniyavneshnih-dannyh-dlya-povysheniya-effektivnosti-raboty-s-klientami.html. 